07

\title{
Электрические характеристики термовольтаического элемента на основе сульфида самария
}

\author{
(C) М.А. Гревцев, С.А. Казаков, М.М. Казанин, В.В. Каминский \\ Физико-технический институт им. А.Ф. Иоффре РАН, \\ 194021 Санкт-Петербург, Россия \\ e-mail: vladimir.kaminski@mail.ioffe.ru
}

Поступило в Редакцию 28 июня 2019 г.

В окончательной редакции 19 марта 2020 г.

Принято к публикации 31 марта 2020 г.

Рассмотрен преобразователь тепловой энергии в электрическую на основе термовольтаического эффекта. В качестве рабочего материала использованы полученные высокотемпературным спеканием образцы сульфида самария $(\mathrm{SmS})$. Определены основные электрические характеристики термовольтаического элемента на основе термовольтаического эффекта: вольт-амперная характеристика, максимальная мощность, внутреннее сопротивление. Показано, что оптимальная нагрузка для получения максимальной мощности равна внутреннему сопротивлению элемента.

Ключевые слова: преобразование энергии, термовольтаический эффект, сульфид самария, мощность, термовольтаический элемент.

DOI: $10.21883 /$ JTF.2020.10.49807.247-19

\section{Введение}

Принцип действия большинства современных термоэлектрогенераторов (ТЭГ) основан на эффекте Зеебека, что предполагает наличие градиента температуры на противоположных спаях термоэлемента [1]. Создание для классического ТЭГ градиента температур в ряде случаев может быть связано с большими трудностями, поэтому весьма перспективными являются исследования ТЭГ, работающих в условиях отсутствия внешнего градиента температуры. Одним из вариантов таких устройств могут быть ТЭГ, работающие на основе термовольтаического эффекта (ТВЭ) [2]. Физический механизм возникновения ТВЭ, описанный в [2], достаточно сложен и не вполне ясен в деталях. В связи с этим представляет интерес исследование электрических характеристик термоэлектрического элемента, работающего на основе ТВЭ.

\section{1. Эксперимент}

Исследуемый термовольтаический элемент (ТЭ) (рис. 1) был изготовлен, согласно [3], и состоял из поликристалла полупроводникового $\mathrm{SmS}$ размерами $10 \times 5 \times 5 \mathrm{~mm}$, который был припаян с помощью металлического самария к кобальтовой пластине. Токовыводы присоединялись к этой пластине и поликристаллу $\mathrm{SmS}$. В процессе пайки и последующего отжига имела место диффузия самария в объемный образец $\mathrm{SmS}$ с образованием градиента избыточных ионов самария, необходимого для возникновения ТВЭ.
Измерения электрических характеристик полученного ТЭ проводились снятием зависимости генерируемого напряжения и температуры от времени. Токовыводы подсоединялись к противоположным поверхностям ТЭГ. При этом в полупроводниковом $\mathrm{SmS}$ в направлении градиента локальной концентрации избыточных ионов самария при определенных температурах образца регистрировалось электрическое напряжение (ТВЭ). Результаты таких измерений представлены на рис. 2. При максимальной температуре эксперимента осуществлялось подключение различных нагрузочных сопротивлений. При замыкании цепи на полезную нагрузку (спад на кривой 1 , рис. 2) появляется электрический ток и фиксируется падение напряжения. Отключение нагрузки приводит к восстановлению исходного напряжения. Для расчета параметров ТЭГ использовалась полученная в эксперименте вольт-амперная характеристика (BAX).

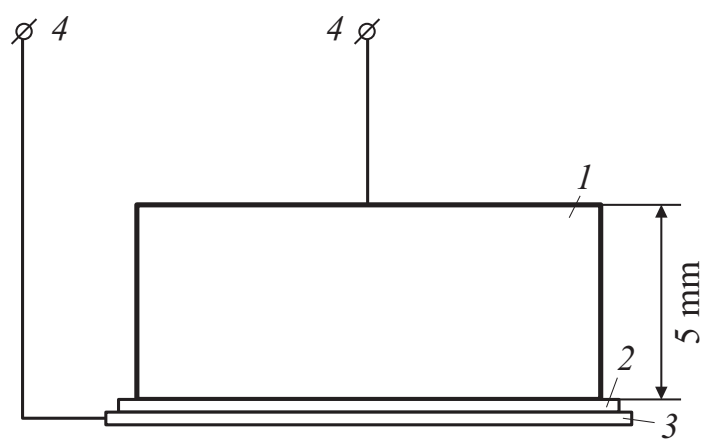

Рис. 1. Схематическое изображение ТВЭ: 1 - поликристалл полупроводникового $\mathrm{SmS}, 2$ - металлический самарий, 3 - пластина из $\mathrm{Co}, 4$ - токовыводы. 


\section{2. Результаты}

„Ступеньки“ на спаде кривой 1 на рис. 2 соответствуют падению напряжения при подключениях полезной нагрузки различной величины от 1000 до $0.5 \Omega$.

Как известно [1], в режиме короткого замыкания ток максимален и равен $I_{s c}$. BAX представляет собой прямую линию, образующую с осью электрического тока угол $\beta$, причем $\operatorname{tg} \beta=r_{t e}$, где $r_{t e}-$ внутреннее сопротивление ТВЭ. На рис. 3 приведена полученная в эксперименте типичная ВАХ элемента на основе сульфида самария. При этом ток короткого замыкания в данном случае оказался равным $I_{s c}=14.5 \mathrm{~mA}$.

Зависимость мощности ТЭ от электрического тока (рис. 4) может быть оценена с использованием ВАХ (рис. 3) и формулы: $P=I \cdot\left(U-I \cdot r_{t e}\right)$.

Квадратичная парабола (рис. 4) показывает, что при максимальной мощности рабочий ток $I \approx 0.5 \cdot I_{s c}$. Подключение нагрузочных сопротивлений осуществлялось при температуре $T=453 \mathrm{~K}$. Оценки внутреннего со-

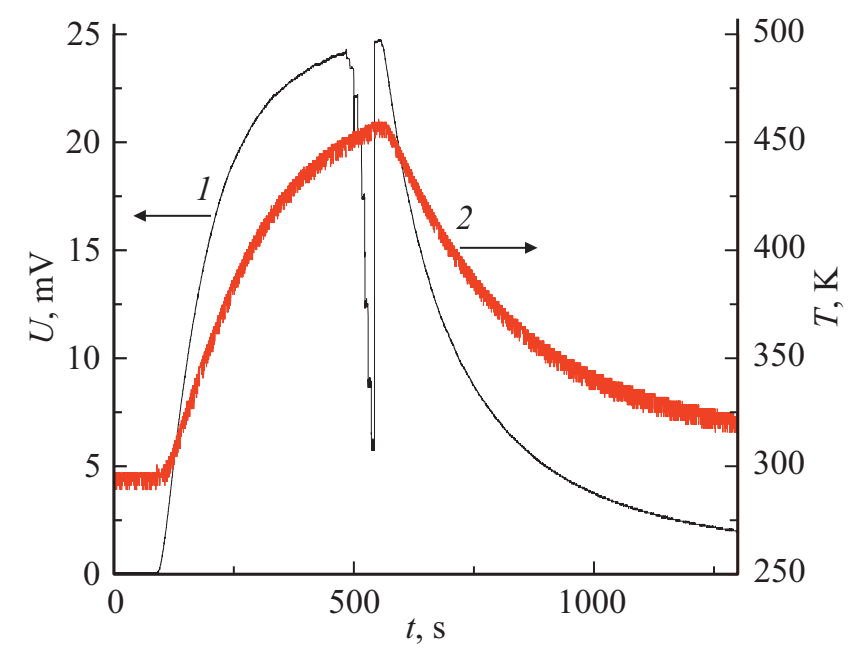

Рис. 2. Зависимости генерируемого ТВЭ на основе сульфида самария напряжения (1) и температуры (2) от времени.

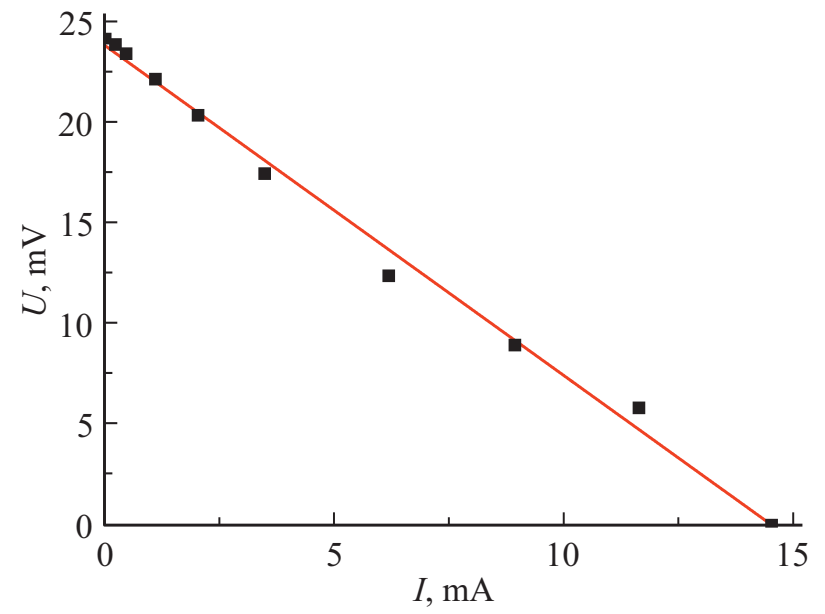

Рис. 3. ВАХ ТВЭ.

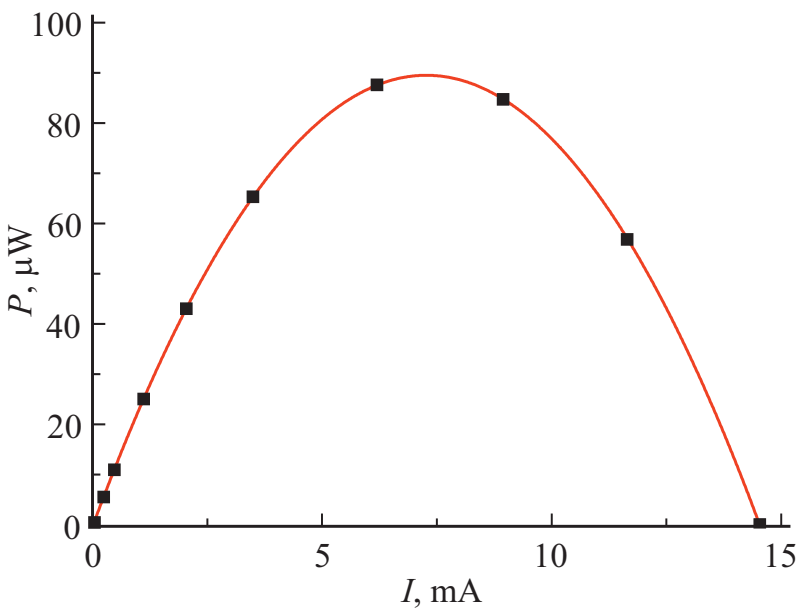

Рис. 4. Зависимость мощности, генерируемой ТВЭ на основе сульфида самария, от электрического тока.

противления $r_{t e}$ по ВАХ и по зависимости мощности от тока дали примерно одинаковую величину $\sim 1.5 \Omega$. Максимальная мощность соответствует $R_{p}=r_{t e}$, как и для эффекта Зеебека [1].

\section{Выводы}

Полученные в ходе исследования экспериментальные данные свидетельствуют о том, что ТВЭ, изготовленные на основе спеченных поликристаллических объемных образцов сульфида самария, могут быть включены стандартным образом в электрические цепи аналогично ТЭГ, работающих на эффекте Зеебека. Показано, что оптимальная нагрузка для получения максимальной мощности равна внутреннему сопротивлению элемента, как и для эффекта Зеебека.

\section{Финансирование работы}

Работа выполнена при поддержке Российского фонда фундаментальных исследований (проект № 19-08-00576 A).

\section{Конфликт интересов}

Авторы заявляют, что у них нет конфликта интересов.

\section{Список литературы}

[1] Охотин А.С., Ефремов А.А., Охотин В.С., Пушкарский A.C. Термоэлектрические генераторы. М.: Атомиздат, 1976. $320 \mathrm{c}$.

[2] Каминский В.В. // Письма в ЖТФ. 2013. Т. 39. Вып. 15. C. $12-17$.

[3] Каминский В.В., Казанин М.М., Казаков С.А., Гревцев М.А., Шаренкова Н.В. Способ изготовления термоэлектрического генератора. Патент РФ на изобретение № 2628677. Приоритет от 01.03.2016. Опубликовано 21.08.2017 в Бюл. № 24. 